\title{
MOBILIÁRIO PORTUGUÊS NA COLECÇÃO \\ DO MUSEU MEDEIROS E ALMEIDA
}

\author{
PORTUGUESE FURNITURE IN THE COLLECTION OF \\ THE MEDEIROS E ALMEIDA MUSEUM
}

Cristina Carvalho*

Conservadora Técnica Superior. Casa-Museu Medeiros e Almeida

\section{Resumo}

Neste artigo, pretendemos dar a conhecer algumas peças de mobiliário português de meados e segunda metade do século XVIII, que integram a colecção reunida por António de Medeiros e Almeida (1895-1986), empresário português, coleccionador de artes decorativas.

Época de relevo na produção nacional de mobiliário, o grupo de peças do Museu Medeiros e Almeida é representativo da excelente qualidade estética e técnica atingida neste período, o qual tantas vezes cruza a madeira exótica chegada do Brasil, com o gosto nacional da madeira entalhada, pouco profunda, seguindo padrões estéticos rococó em que as formas se contraem. O excesso de volumes, as ondulações acentuadas e a ostentação dourada características do barroco, por vezes coexistem com eles, noutros casos vão progressivamente desaparecendo.

A colecção integra tipologias variadas que permitem observar a adesão aos padrões de gosto inglês e francês, cuja simbiose se revelou no móvel português.

Palavras-chave: Portugal, século XVIII, móvel, rocaille, pau-santo, talha

\section{Abstract}

The purpose of this paper is to present the Portuguese furniture (from mid and second half of the $18^{\text {th }}$ century) gathered by António de Medeiros e Almeida (1895-1986), Portuguese businessman and collector of decorative arts.

The Medeiros e Almeida Museum pieces are representative of the unique aesthetic and technical quality achieved, during the golden period of the Portuguese furniture, which often brings together the exotic wood from Brazil and the national taste for carved wood, with rococo patterns. The excess of volumes, the accentuated waves and the gilded ostentation, characteristic of the Baroque period, sometimes coexists with them and in other cases tends to disappear.

The collection includes different types of pieces that reveal the English and French influences, resulting in a new kind of the Portuguese furniture.

Keywords: Portugal, $18^{\text {th }}$ century, furniture, rocaille, rosewood, carving 
António de Medeiros e Almeida (1895-1986) (Fig.1) foi um empresário, colecionador e filantropo português, que, em 1972, legou ao país toda a sua coleção, criando uma Casa-Museu, (Fig.2) em Lisboa, gerida por uma fundação com o seu nome. A colecção de artes decorativas por si criada é constituída por um eclético acervo que inclui cerâmica da China, têxteis, pratas, relógios, pintura, escultura, leques e mobiliário.

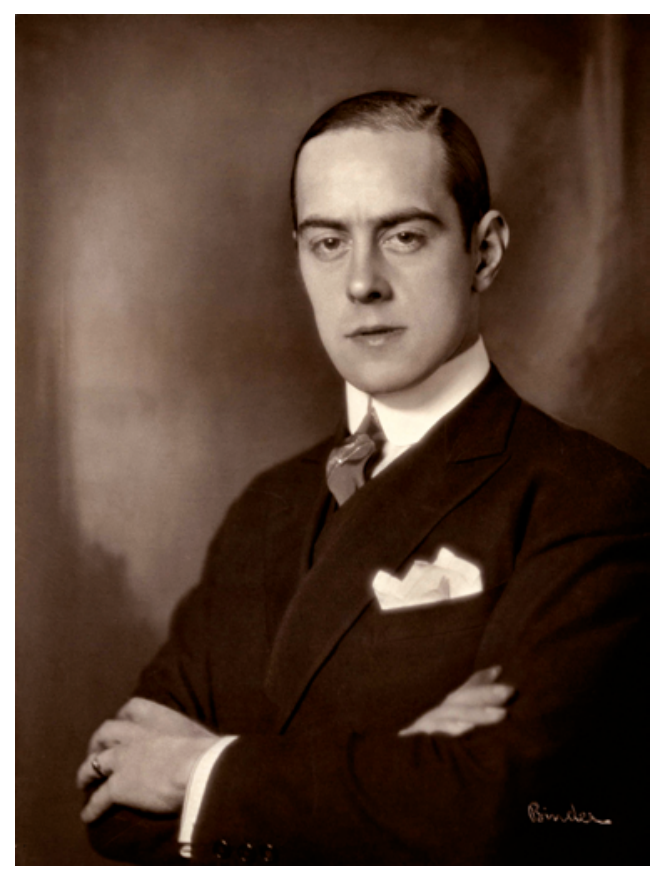

Fig. 1 António Medeiros e Almeida (1895-1986). (c) Casa-Museu Medeiros e Almeida.

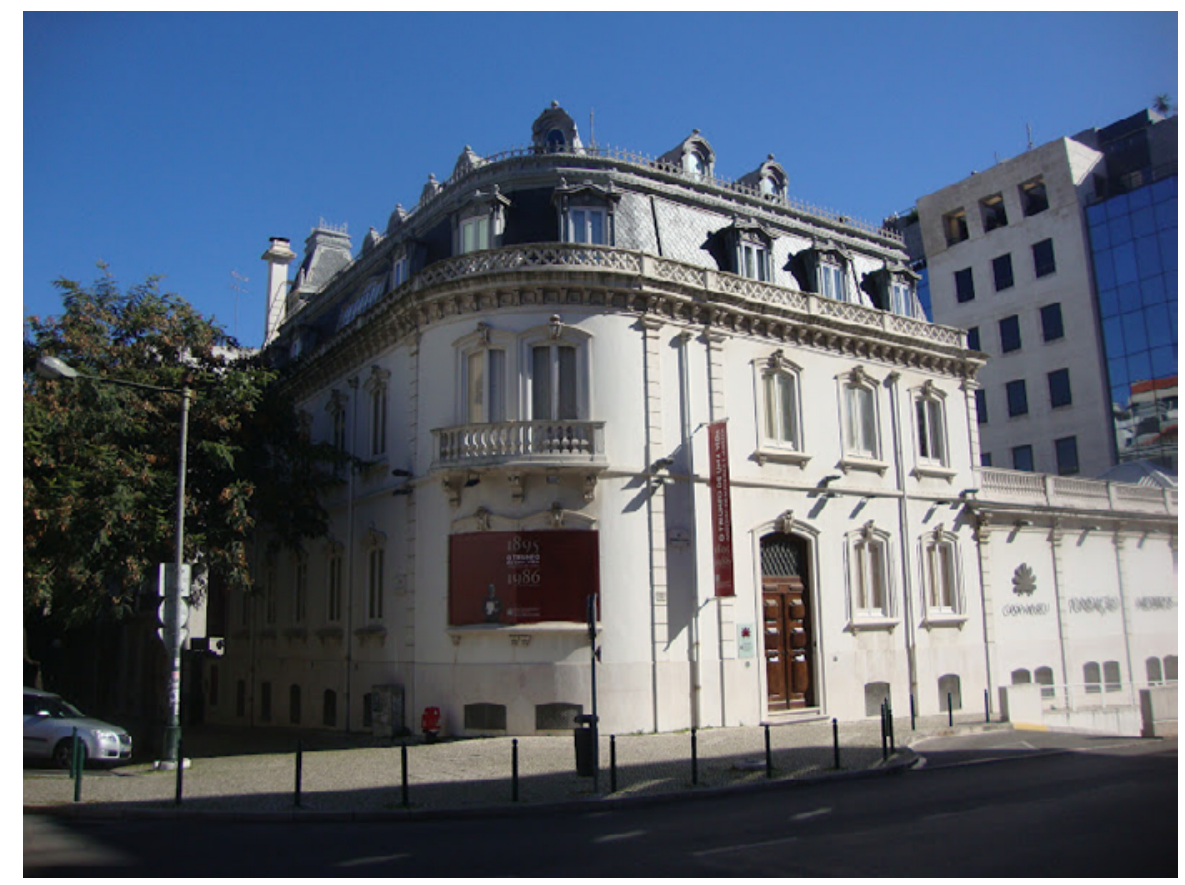

Fig. 2 Museu Medeiros e Almeida. (c) Casa Museu-Medeiros e Almeida. 
Neste artigo, pretendemos dar a conhecer algumas das peças de mobiliário português que a integram, nomeadamente as do período dos reis D. João $\mathrm{V}$ (r. 1706-1750) e D. José I (r. 1750-1777).

Do primeiro período, possui o acervo um par de cómodas em nogueira com decoração entalhada e dourada e tampo de mármore que reflecte as exuberantes características barrocas do mobiliário português do reinado do Magnânimo, no qual as influências francesas, inglesas, mas também de Roma, estiveram sempre presentes. ${ }^{1}$

Da época correspondente ao reinado de D. José, integram a coleç̧ão exemplares diversificados: uma cómoda - papeleira em nogueira, uma mesa de 4 tampos, uma espreguiçadeira, uma mesa de encostar, variadas tipologias de móveis de assento.

O grupo de peças do Museu Medeiros e Almeida (MMA) aqui apresentado é representativo da excelente qualidade estética e técnica atingida neste período, pelo mobiliário de produção nacional.

Na segunda metade do século XVII, Inglaterra assume um papel de destaque, influenciando o gosto, fruto do casamento com Carlos II com D. Catarina de Bragança e da sua estadia neste país, assim como posteriormente, do tratado de Methuen. ${ }^{2}$

As persistências nos primeiros decénios do século XVIII, quando em França o rocaille já despontava, perduram no gosto pelo mobiliário do século XVII, no entanto, lentamente, novas formas e apontamentos decorativos vão surgindo nos móveis portugueses. Pernas galbadas, tabelas onduladas, madeiras entalhadas, motivos decorativos de cariz barroco, uso de madeira dourada, ${ }^{3}$ permitindo assim esta assimilação, o surgimento de características tipicamente portuguesas transformando-se o móvel nos reinados de D. João V e D. José.

A colecção integra exemplares onde é possível identificar características inglesas e francesas cuja simbiose com o gosto português originou peças de uma nova estirpe.

Os móveis começam a apresentar algumas particularidades inglesas (dos períodos Queen Anne e de George I e posteriormente Chippendale): espaldares dos móveis de assento de forma ondulada com tabelas recortadas, as pernas galbadas e os pés de diferentes tipos de garra e bola ${ }^{4}$, como no caso das cadeiras em nogueira com espaldar e assento em palhinha (Fig.3), ou nas de assento em couro persistência ainda, de um gosto enraizado ao longo de mais de 100 anos. A influência inglesa é também visível nos pés de ave de rapina que seguram bola, do par de cómodas ou dos móveis de assento.

A decoração de gosto barroco surge simetricamente entalhada não faltando o apontamento dourado tão ao gosto francês que, entretanto, também se impõe e coexiste, como por exemplo, no avental do par destas cómodas (Fig.4). Das tonalidades escuras do século anterior, os móveis passam a apresentar apontamentos dourados, reflectindo desta forma a tão desejada ostentação, como aqueles que vemos na talha que decora as mesmas cómodas.

O longo reinado de D. João V (1706-1750) assistiu a uma evolução do gosto, em particular em França, em que o barroco se transforma em rocaille a partir da década de 1730, com a criação e publicação de novos ornamentos de cariz assimétrico e 11 esvoaçante ${ }^{5}$. Tais modificações também foram conhecidas 
e adoptadas em Portugal mas apenas no $3^{\circ}$ quartel do século XVIII, originando desta forma um novo gosto coincidente com o reinado de D. José. Agora a leveza decorativa impera, assim como o movimento assimétrico, seguindo os modelos decorativos franceses e alemães de Augsburgo ${ }^{6}$ Marceneiros portugueses entalham com pouca espessura seguindo desenhos que chegavam a Portugal, aprimorando a sua técnica decorativa e construtiva anteriormente apreendida na construção retabular ${ }^{7}$ e transposta para o mobiliário como no paradigmático caso da decoração das ilhargas da cómoda-papeleira decoradas por cartelas de forma claramente rocaille, com concheados, asas de morcego, folhagem que se desenvolve exuberante de forma simétrica, ao gosto rococó francês no qual a assimetria total nunca dominou, contrastando com os modelos que chegavam de Augsburgo. ${ }^{8}$

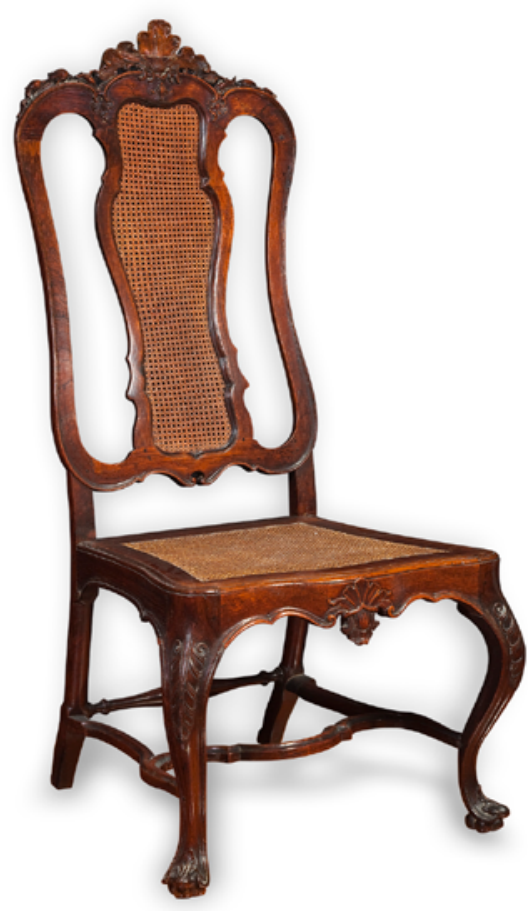

Fig.3 Cadeira - FMA 201-202. Portugal, séc. XVIII - meados. Pau-santo, palhinha. A: $117 \mathrm{~cm}$ x L:55,5cm x P:57cm. (C) Casa Museu-Medeiros e Almeida.

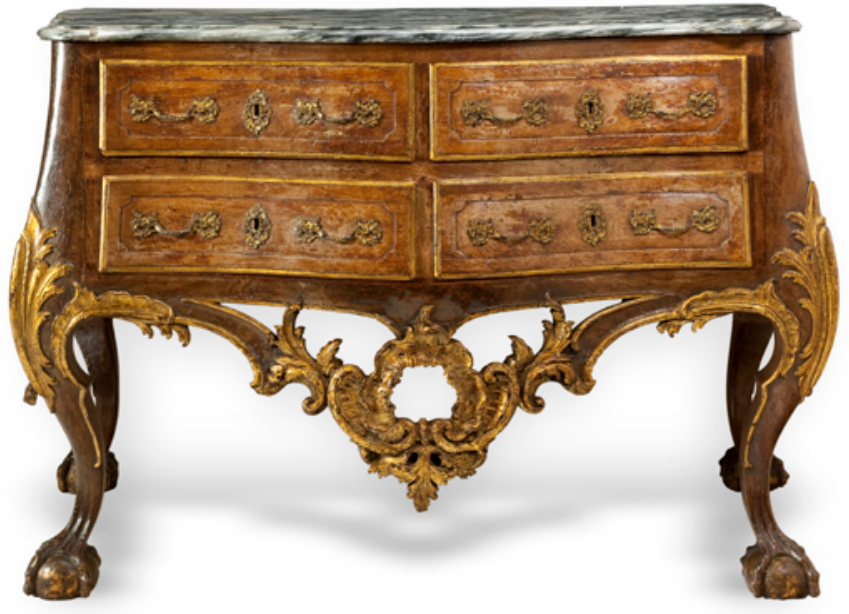

Fig. 4 Cómoda (par) - FMA 35 - 36. Portugal, séc. XVIII - meados. Nogueira, mármore. A:96,5cm x L:130cm x P:77cm. CC Casa Museu-Medeiros e Almeida.

De França chega também a elegância das pernas galbadas, finas com ondulação suave, característica que será adoptada em Portugal em muitos dos seus móveis. De facto, as pernas da mesa de encostar da coleç̧ão apresentam esta particularidade fazendo do seu marceneiro um exímio executor, dada a sua altura e pouca espessura, subindo até ao tampo, integrando a cintura, distintivo das peças feitas em Portugal. As mesas de encostar podiam ainda apresentar na cintura uma "quebra" vertical, acentuando desta forma a sua ondulação, tal como no caso do mesmo exemplar em pau-santo sobriamente entalhado, mas de grande qualidade de execução. 
Específico da marcenaria portuguesa do terceiro quartel do século XVIII, foi a associação das madeiras exóticas com a contenção decorativa da talha esculpida com pouca espessura numa simbiose de influência inglesa ${ }^{9}$ com o gosto português e que aqui se traduz na mesa de quatro tampos em pau-santo (Fig.5). Decorada por entalhamento parcimonioso, revela a mestria da execução do mobiliário português deste período, conjugada com a riqueza de materiais que a integram: pau-santo, marfim, pau-rosa, buxo, limoeiro e bronze. De autor desconhecido até ao momento, a mesa apresenta quatro tampos que se "desfolham" como um livro, permitindo uma multiplicidade de funções: mesa de encostar (Fig.6), de jogo (Fig.7), de xadrez, damas, gamão (Fig. 5), de centro (Fig.8) ou chá e ainda de toilette. De perfil ondulado, o aro com quatro gavetas, duas das quais fingidas, integra três pernas galbadas que terminam em pé de cachimbo. No tardoz, apresenta um apoio articulado que permite abrir mais uma perna e suportar os diversos tampos quando abertos. O seu autor certamente teria conhecimento de mesas de jogo inglesas cujos tampos articulados se abriam sendo suportadas por uma perna móvel também articulada, que recolhia na traseira da mesa. Esta técnica construtiva existe já no século XVII, com as designadas gate-leg table ${ }^{10}$ cujo mecanismo, grosso modo, é o mesmo apenas se diferenciando pela existência de travejamento para maior estabilidade.

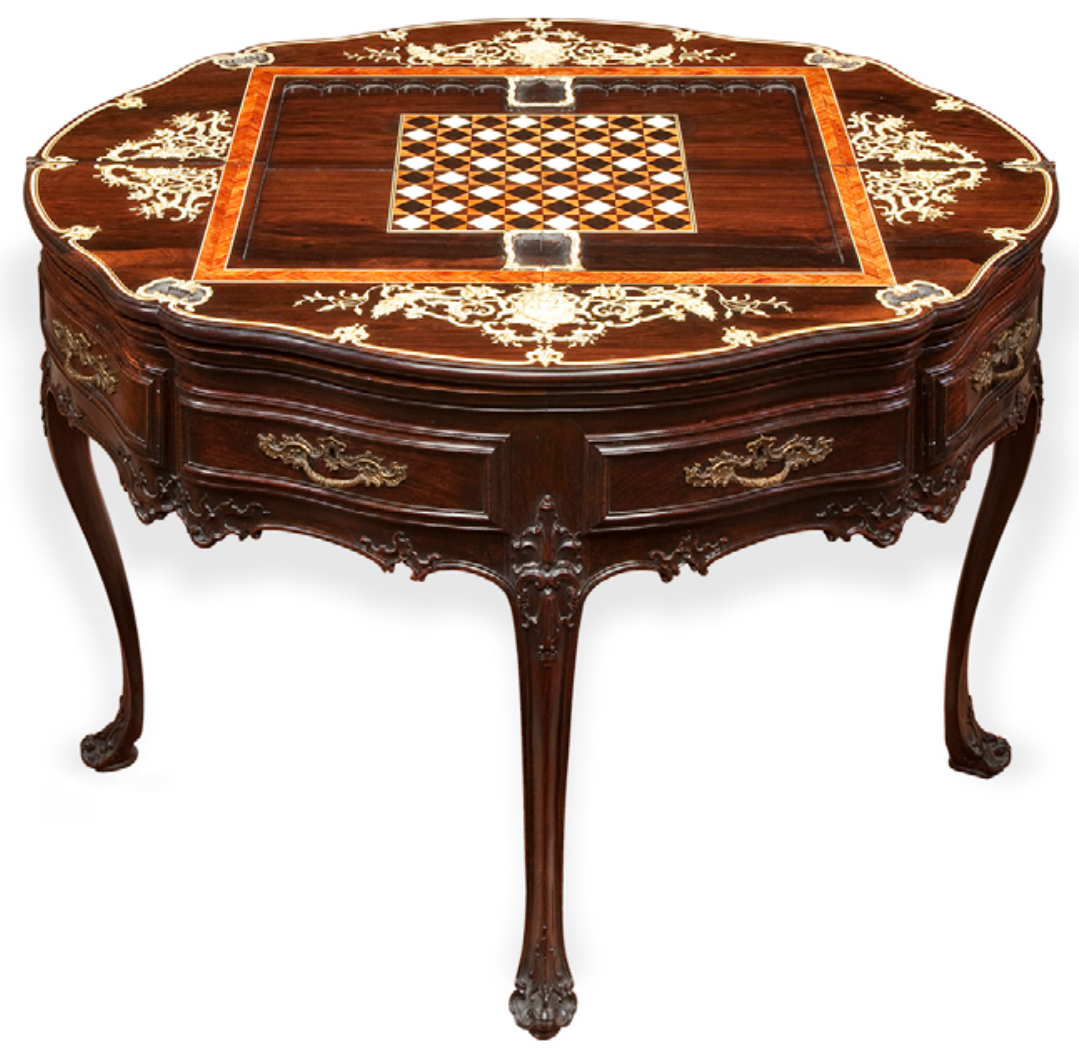

Fig. 5 Mesa 4 tampos - FMA 299. Portugal, séc. XVIII - 3º quartel. Pau-santo, marfim, buxo, limoeiro, bronze (gamão, xadrez, damas) . A:74cm x D:100cm . C Casa Museu-Medeiros e Almeida. 


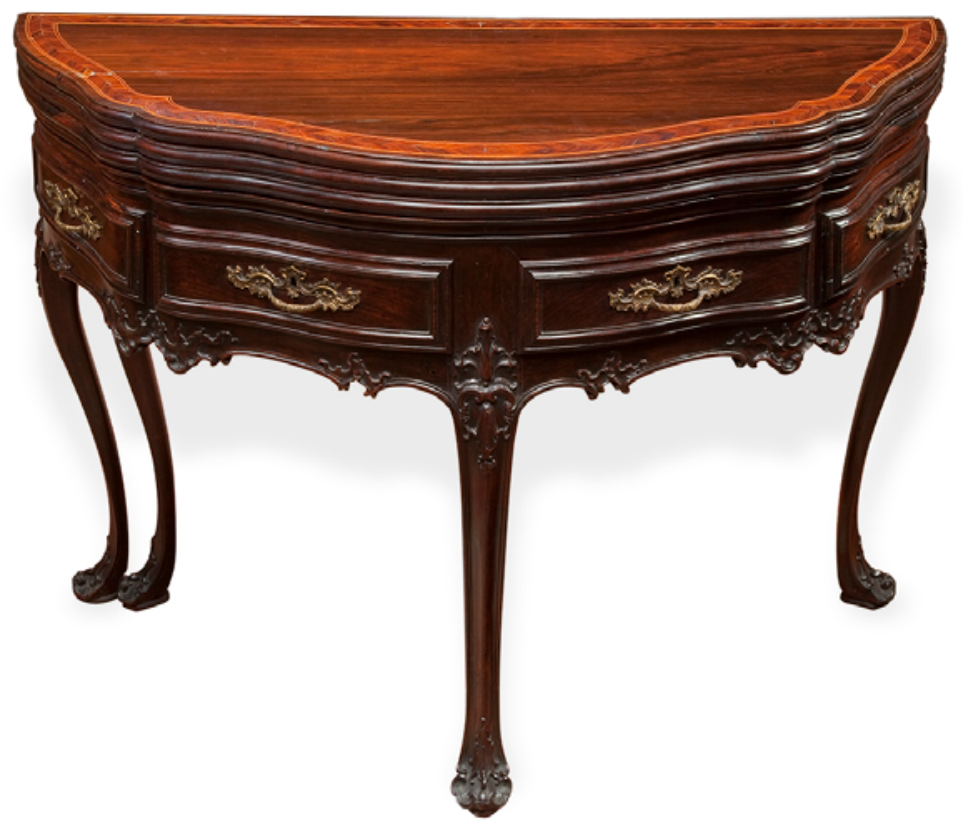

Fig. 6. Mesa 4 tampos (fechada - encostar) - FMA 299. Portugal, séc. XVIII - $3^{\circ}$ quartel. Pau-santo, marfim, buxo, limoeiro, bronze. (c) Casa Museu-Medeiros e Almeida.

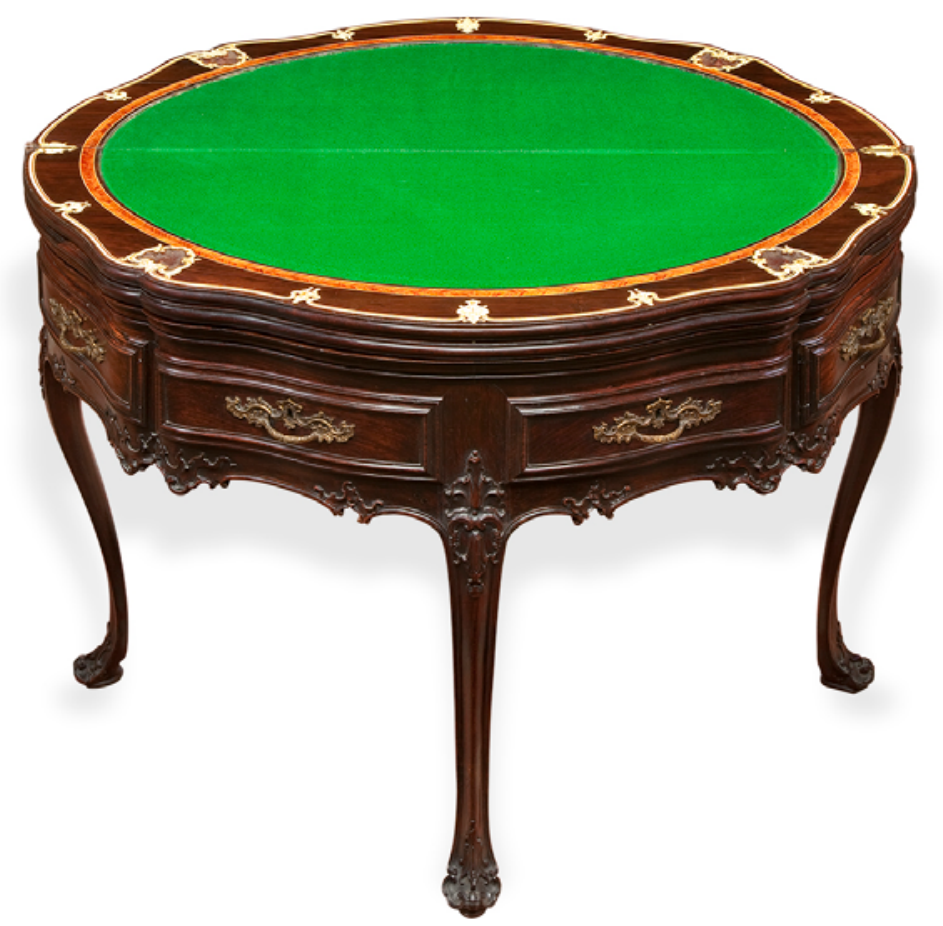

Fig. 7. Mesa 4 tampos (jogo) - FMA 299. Portugal, séc. XVIII $-3^{\circ}$ quartel. Pau-santo, marfim, buxo, limoeiro, bronze. C Casa Museu-Medeiros e Almeida. 


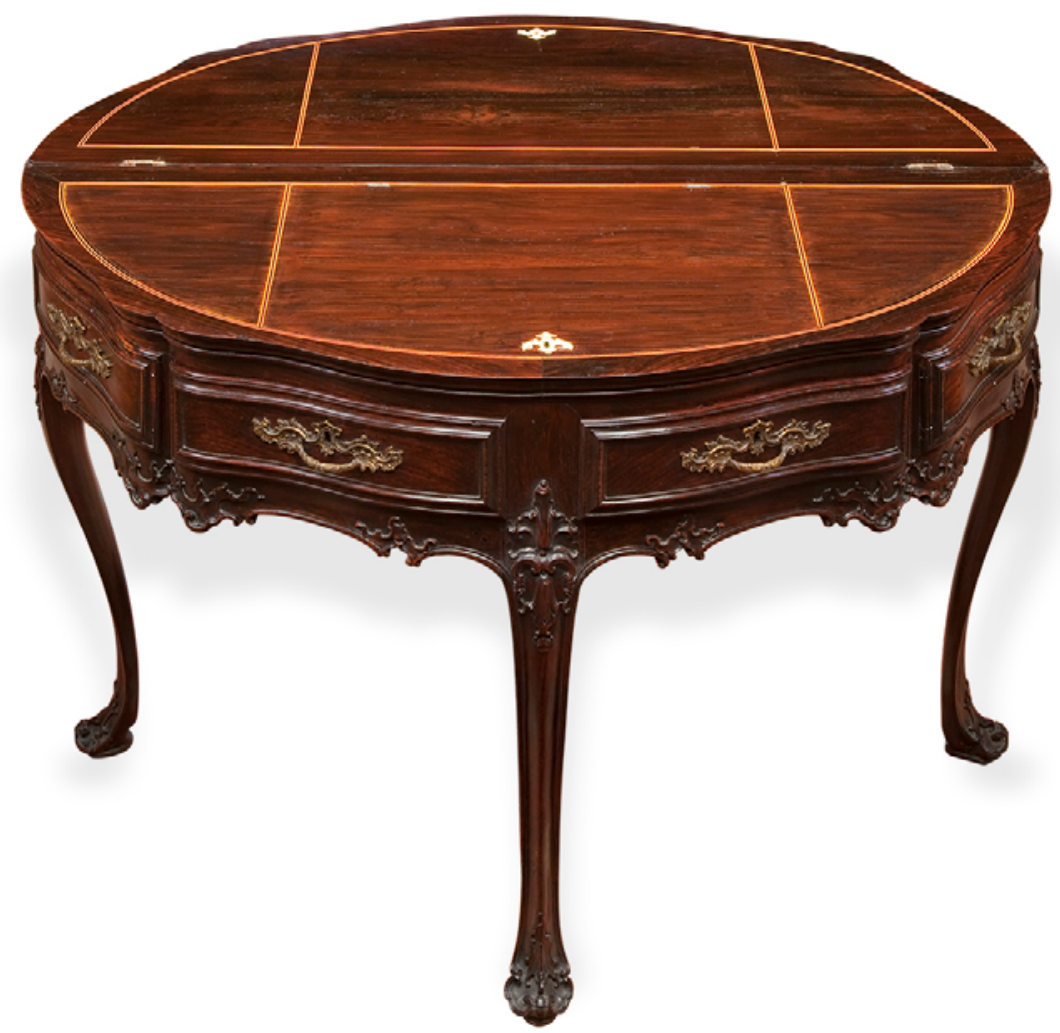

Fig. 8. Mesa 4 tampos (centro) - FMA 299. Portugal, séc. XVIII - $3^{\circ}$ quartel. Pau-santo, marfim, buxo, limoeiro, bronze. (C) Casa MuseuMedeiros e Almeida.

No interior guarda ainda três segredos: duas gavetas colocadas no vão entre o toucador e o perfil da mesa acompanhando-o e ainda uma terceira gaveta disposta paralelamente ao entrepano, possivelmente destinada a guardar peças de jogo. Apenas são alcançáveis através da remoção total das gavetas que permite o acesso ao vão. A discreta talha baixa, ondulada, recortada e assimétrica, de folhagem estilizada segue padrões de gosto rococó, tal como os puxadores em bronze dourado.

Por outro lado, a escolha do tipo de madeiras também veio a caracterizar a produção portuguesa que virá a ter uma clara predilecção pelas madeiras exóticas, em particular pelo pau-santo trabalhado de forma maciça ${ }^{11}$, como em diversos casos aqui referidos.

De forma paralela, as madeiras autóctones foram também muito usadas, especialmente a nogueira que se tornou numa das preferidas dos marceneiros portugueses, dado o resultado final da obra, a facilidade de acesso e aptidão para ser trabalhada. ${ }^{12}$ É desta madeira uma das peças mais emblemáticas da colecção: a cómoda - papeleira (Fig.9) de formas vincadamente onduladas que se transpõem no seu interior. A peça é de grande perícia de execução tanto do ponto de vista estrutural como decorativo. Assenta sobre pés em sapata que poderemos remeter para inspiração inglesa de Thomas Chippendale ${ }^{13}$ no seu The Gentleman and Cabinet Maker's Director, onde surgem várias propostas 
de pés de papeleiras (com alçados) que se aproximam desta forma. A frente constituída por quatro gavetas apresenta uma estrutura ondulada acentuada. As quatro prumadas rematadas por colunas tridimensionais formando enrolamentos (com vazados) e folhagem assumem uma dimensão e profundidade pouco comuns, como pouco comum é a existência destas no tardoz do móvel. O uso de colunas tridimensionais nas prumadas das papeleiras popularizado no $3^{\text {o }}$ quartel do século XVIII, remete para o gosto inglês ${ }^{14}$, mas de uma maneira geral, bem mais discreto.

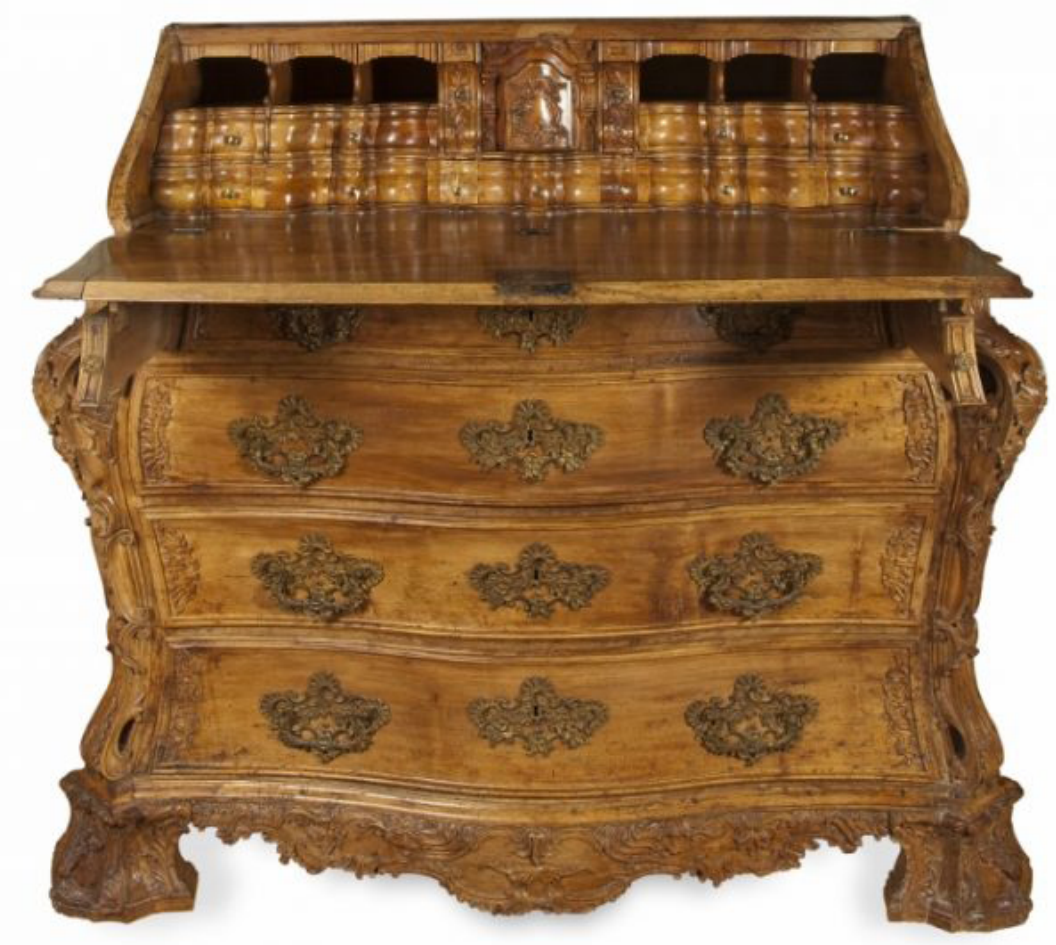

Fig. 9 Papeleira - FMA 177. Portugal, séc. XVIII - $3^{\circ}$ quartel. Nogueira, bronze. A:127cm x L:133 x P:72cm. (C) Casa Museu-Medeiros e Almeida.

Nesta peça, o autor certamente procurou inspiração nos inúmeros desenhos (franceses e ingleses?) que à época circulavam em Portugal. De facto, toda a sua decoração revela não só uma execução aprimorada, como erudição do ponto de vista decorativo, dada a riqueza e complexidade dos motivos escolhidos. Provavelmente, a peça terá tido um alçado (poderia ser um oratório ou um armário e apresentar "duas meias portas com espelho"15), dado o remate no topo da mesma.

As ferragens também de gosto rocaille apresentam pequenos cachos de uvas, numa variante de um modelo inglês apresentado no volume $\mathrm{V}$ do Book of Steel, importante fonte iconográfica inglesa do século XVIII e conhecida em Portugal. ${ }^{16}$ 
Existe um outro exemplar quase igual a este em colecção particular, com pequenas variações ao nível da decoração da talha, diferindo apenas ligeiramente nas dimensões e no material de execução: o pau-santo. ${ }^{17}$

Também de nogueira é o par de cómodas (Fig. 4) com tampo de mármore e exuberante talha volumosa e dourada, com pernas galbadas com joelhos salientes terminando em bola envolvida por garra de ave de rapina. A talha que se espalha de forma simétrica pelo avental com concheados, acantos estilizados, enrolamentos indicia o gosto francês, preconizando já um novo período, o rocaille, através dos vazados e da movimentação assimétrica da decoração das ilhargas. O douramento dos motivos decorativos, pode remeter a sua execução para algum tempo antes de 1749, ano em que é publicada por D. João V, a Pragmática que proibia o uso de ouro no mobiliário ${ }^{18}$, levando-nos a equacionar a hipótese de integrar estas peças num período de transição entre o reinado de D. João V e D. José I e no qual as formas barrocas são ainda visíveis, mas onde começam a despontar elementos mais leves, vazados, ${ }^{19}$ como neste caso.

A evolução do gosto fez-se também através da conjugação de novidades e persistências como no caso do conjunto de seis cadeiras em pau-santo e couro lavrado, adquiridas em 1961, no leilão dos herdeiros do coleccionador Alfredo Guimarães. ${ }^{20}$

Executadas em madeira maciça com as prumadas que integram a cintura do assento, com coxim móvel em couro lavrado com motivo de xadrez, tão ao gosto português do século XVII, as peças apresentam claras influências inglesas tendo resultado a sua assimilação e reinterpretação numa característica portuguesa. $\mathrm{O}$ facto de as peças apresentarem uma tabela em forma de balaústre, pernas galbadas estabilizadas por travejamento em $\mathrm{H}$ ondulado e pés em cachimbo, dão-nos os referentes ingleses, que resultou num tipo de cadeira que se popularizou em Portugal na qual o cachaço surge vazado.

A mesma premissa apresenta o par de cadeiras em pau-santo entalhado, com assento e tabela recortada em palhinha (Fig. 3) que foi adquirido em leilão da Sotheby's em Londres, em 1973.

Desconhece-se a proveniência e forma de integração de um conjunto de cadeiras e canapé em pau-santo entalhado com assento móvel estofado (moderno). O conjunto segue o tradicional gosto da marcenaria portuguesa pelo pau-santo e pelo cachaço entalhado com pluma, flores e concheados. Do ponto de vista estrutural e decorativo inspira-se claramente na influência inglesa, ao apresentar pernas apoiadas directamente sob a cintura, espaldar trapezoidal com tabela vazada, replicando vários espaldares individuais, muito próxima dos modelos propostos por Chippendale, contrastando com os pés de garra e bola e o assento (ainda) ondulado, numa simbiose de gostos que deram origem a peças caracteristicamente portuguesas. ${ }^{21}$

Muito populares em Portugal foram os leitos de dia designados por espreguiçadeira, (Fig. 10) camilha ${ }^{22}$, espreguiceiro, espreguiçador, preguiceiro... ${ }^{23}$ tudo referências para um mesmo móvel, especificamente destinado à sesta. Executada em pau-santo com talha baixa, apresenta cabeceira constituída por espaldar ligeiramente inclinado, recortado formando cartela central forrada a seda e por prumadas rematadas por pináculos de concheados assimétricos. Cachaço recortado e vazado, o barramento ondulado, é decorado 
por concheado entalhado. Assenta sobre oito pernas galbadas que integram a cintura do móvel, com joelho entalhado e pouco saliente e pés de cachimbo ornamentado por folha de acanto. Parafusos de armar em bronze dourado. O móvel apresenta um estrado em couro lavrado formando cercadura de motivos rocaille com folhagem estilizada em curva e contracurva cujo medalhão central assimétrico segue idêntica estética. No $3^{\circ}$ quartel do século XVIII, as características rocaille acentuam-se no entanto, ainda é visível a persistência do gosto pelo couro lavrado que transitou do século anterior.

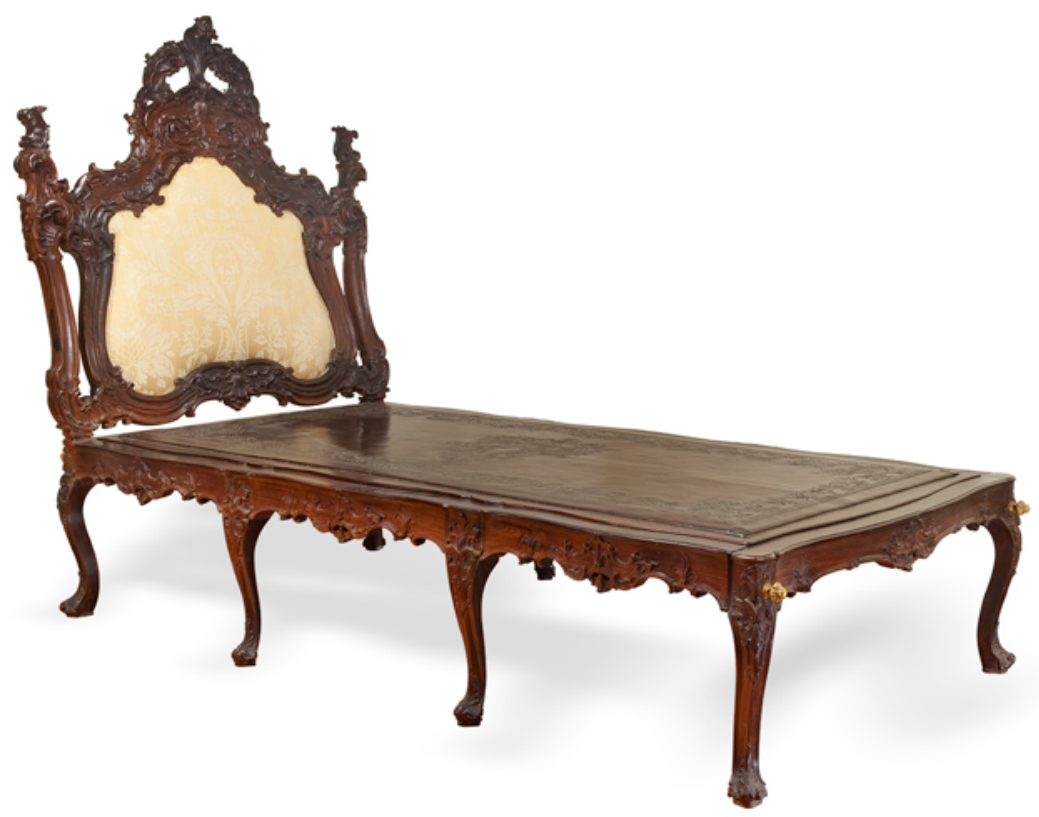

Fig. 10. Figura 10 Espreguiçadeira - FMA 479. Portugal, séc. XVIII - $3^{\circ}$ quartel. Pau-santo, couro, seda. A: $202 \mathrm{~cm} \mathrm{x} \mathrm{L:} \mathrm{104,7cm} \mathrm{x} \mathrm{C:} 165 \mathrm{~cm}$. (C) Casa Museu-Medeiros e Almeida.

\section{Considerações finais}

Pretendemos dar uma visão de conjunto embora não exaustiva, das peças de mobiliário português do século XVIII que integram o acervo do MMA, contribuindo assim, para o seu conhecimento e divulgação.

Não nos é possível rastrear toda a história e/ou proveniência das mesmas uma vez que, estas foram sendo adquiridas ao longo do tempo pelo coleccionador em antiquários e leilões tanto em Portugal como no estrangeiro, deixando em aberto inúmeras questões quanto à sua origem e que poderiam contribuir para um melhor conhecimento das mesmas, assim como, do mobiliário português destes períodos.

Ficamos, porém, com a certeza que, as peças são representativas da qualidade e características inerentes ao mobiliário produzido no período correspondente a parte do reinado de D. João V e D. José I, época áurea do móvel português, reflexo também de uma sociedade em mutação na qual, a busca pelo conforto e refinamento se expande, tanto na corte como na aristocracia, sem nunca esquecer totalmente o aparato. 


\section{NOTAS}

${ }^{1}$ José António Proença, Mobiliário da Casa Museu Anastácio Gonçalves (Lisboa: Instituto Português de Museus, 2002), 23.

${ }^{2}$ Proença, Mobiliário da Casa Museu Anastácio Gonçalves, 21.

${ }^{3}$ Proença, Mobiliário da Casa Museu Anastácio Gonçalves, 22.

${ }^{4}$ Proença, Mobiliário da Casa Museu Anastácio Gonçalves, 21-22.

${ }^{5}$ Vd. Juste-Aurèle Meissonier, Oeuvre de Juste-Aurèle Meissonnier $[\mathrm{s} / \mathrm{d}]$ ou Livre d'Ornemens $[\mathrm{s} / \mathrm{d}]$

${ }^{6}$ Proença, Mobiliário da Casa Museu Anastácio Gonçalves, 23.

${ }^{7}$ Adelina Valente, "Matrizes Inglesas no Mobiliário Português na Segunda Metade do Século XVIII.” Tese de doutoramento, Universidade Católica Portuguesa, 2014, 95-97.

${ }^{8}$ Bill G.B. Pallot, L'Art du Siège au XVIIIe Siècle en France (Paris : A.C.R. Gismondi Éditeurs, 1987), 132.

${ }^{9}$ Proença, Mobiliário da Casa Museu Anastácio Gonçalves, 26.

${ }^{10}$ Ralph Edwards, Dictionary of English Furniture (London: Country Life Limited, 1954), 234-240.

${ }^{11}$ Proença, Mobiliário da Casa Museu Anastácio Gonçalves.

${ }^{12}$ Proença, Mobiliário da Casa Museu Anastácio Gonçalves, 25.

${ }^{13}$ Thomas Chippendale, The Gentleman and Cabinet Maker's Director (reprint of the third edition) (N.Y.: Dover Publications Inc., 1966), est. CVII.

${ }^{14}$ Robert Wemyss Symonds, Furniture-Making in the 17th and 18th Century England (London: The Connaisseur, 1955), 110-111.

${ }^{15}$ Carlos Franco, O Mobiliário das elites de Lisboa na segunda metade do século XVIII (Lisboa: Livros Horizonte, 2007), 103-104.

${ }^{16}$ Valente, "Matrizes Inglesas no Mobiliário Português na Segunda Metade do Séc. XVIII."

${ }^{17}$ Fernanda Castro Freire, 50 dos Melhores Móveis Portugueses (Lisboa: Chaves Ferreira Publicações SA, 1995), 85.

${ }^{18}$ J. F. da Silva Nascimento, Leitos e camilhas portugueses, subsídios para o seu estudo (Lisboa:

Ed. Autor, 1950), 57

${ }^{19}$ Proença, Mobiliário da Casa Museu Anastácio Gonçalves, 23.

${ }^{20}$ Alfredo Guimarães (? - 1923) reuniu na sua residência na rua da Cruz dos Poiais, em Lisboa, uma eclética colecção de artes decorativas que integrava mobiliário (português, indo - português, francês, holandês) faiança portuguesa, porcelana da China e europeia, um presépio em barro, tapetes de Arraiolos... Em 1961, os seus herdeiros (Júlia Guimarães de Mendia de Noronha e Eduardo Alfredo Guimarães de Mendia) leiloaram parte deste recheio através da leiloeira Soares e Mendonça. Foi neste âmbito que António Medeiros e Almeida adquiriu algumas peças.

${ }^{21}$ Proença, Mobiliário da Casa Museu Anastácio Gonçalves, 29.

${ }^{22}$ Fernanda Castro Freire, Guia do Museu de Artes Decorativas Portuguesas (Lisboa: Fundação Ricardo Espírito Santo Silva, 2001), 132.

${ }^{23}$ J. F. da Silva Nascimento, Leitos e camilhas portugueses, est. LX - LXI. 